\title{
Between Denisovans and Neanderthals: Strashnaya Cave in the Altai Mountains
}

Andrey Krivoshapkin ${ }^{1}$, Alena Shalagina ${ }^{1}$, Malvina Baumann ${ }^{2}$, Svetlana Shnaider ${ }^{1} \&$ Kseniya Kolobova ${ }^{1, *}$

New data from Strashnaya Cave have revealed previously unknown complexity in hominin occupation of the Altai Mountains, including the first regional evidence for the presence of anatomically modern humans.

Keywords: Altai, Strashnaya Cave, Middle Palaeolithic, human origins

The Altai Mountains have come to be regarded as a crucial region in the discussion of human origins. Palaeogenetic and palaeoanthropological discoveries have provided evidence for the long-term co-habitation of this area by the Denisovans and Neanderthals, and for genetic flow between these two groups (Slon et al. 2017). The techno-typological features of Altairegion Middle Palaeolithic assemblages have facilitated the identification of three main traditions: the Denisovan, Kara-Bom and Sibiryachikha. The Denisovan and Kara-Bom types reflect an autochthonous development of the local Upper Palaeolithic, Levallois-based industries, and correlate with the evolution of Denisovans into anatomically modern humans (Derevianko et al. 2014).

From 2013-2017, archaeological investigations at the Strashnaya Cave $\left(51^{\circ} 10^{\prime} 26.0^{\prime \prime}-\right.$ $\left.83^{\circ} 01^{\prime} 42.6^{\prime \prime}\right)$ in north-western Altai, Russia (Figure 1) have revealed Middle and Upper Palaeolithic lithic assemblages, human remains and unique bone tools and ornaments. These finds are helping to address the question of the peopling of Northern Asia. A total of 13 lithological layers were identified, with an overall thickness of approximately $10 \mathrm{~m}$ (Figure 2). Layers 1 and 2 are dated to the Holocene, and the underlying layers to the Pleistocene. The Pleistocene layers comprised seven Middle Palaeolithic layers (10-4) and one Upper Palaeolithic layer (3).

Radiocarbon dates allow us to attribute the top part of layer 3 (horizon $3_{1}$ a) to oxygen isotope stage (OIS) 2, while the bottom of layer 3 (horizons $3_{1} \mathrm{~b}$ and $3_{3}$ ) dates to OIS 3 . Absolute dates from layers 4 and 5 correspond to OIS 3, although this does not match the Middle Palaeolithic industry found within these layers. This reflects complex site stratigraphy and disturbance by rodents (Figure 2). New OSL dates are being prepared in order to address this inconsistency. The Middle Palaeolithic assemblages, comprising 3862 items from

1 Institute of Archaeology and Ethnography, Russian Academy of Sciences (Siberian branch), Lavrentieva Avenue 17, 630090 Novosibirsk, Russia

2 University of Bordeaux, Bordeaux, UMR5199 Bâtiment B8, Allée Geoffroy St Hilaire, Pessac Cedex 33615 , France

* Author for correspondence (Email: kolobovak@yandex.ru)

(C) Antiquity Publications Ltd, 2018 ANTIQUITY 92 365, e1 (2018): 1-7 


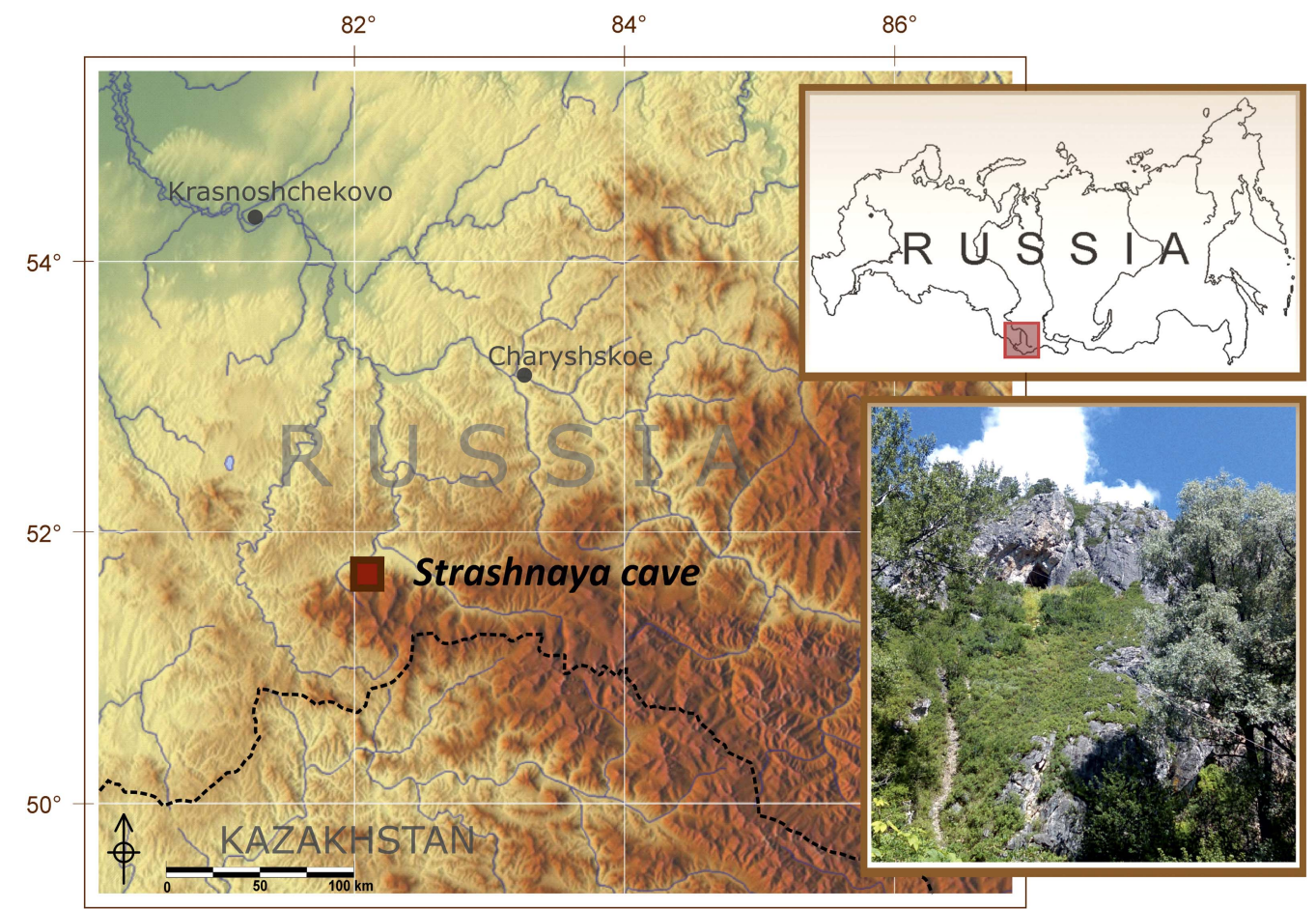

Figure 1. Map of the Altai region showing the Strashnaya Cave.

layers 10-4, are dominated by thick flakes with large striking platforms, created by radial and orthogonal techniques. Levallois convergent and preferential technologies were used to produce points and flakes (Figure 3.6-8). Some artefacts from the Middle Palaeolithic assemblages indicate features of blade production (Figure 3.10). The tool kit comprises various side-scrapers, truncated-faceted tools, retouched points, and notched and denticulate tools (Figure 3.5 \& 3.9).

The Upper Palaeolithic assemblages (1788 items from horizons $33_{1}$ a, $33_{1} \mathrm{~b}$ and $3_{3}$ ) include blade and bladelet prismatic cores, and several radial and Levallois cores. The tool kits comprise end-scrapers, retouched blades and flakes, splintered pieces, borers and sidescrapers (Figure 3.1-4). The bone industry from horizons $3_{1} \mathrm{a}, 3_{1} \mathrm{~b}$ and $3_{3}$ includes: ornaments, bone tools (needles (Figures 4.9-10)), an intermediate tool (Figure 4.16), an awl (Figure 4.15), a burnisher (Figure 4.13), a tool made from red deer antler (Figure 4.14) and three fragments of hunting weaponry (Figure 4.6-8). The ornaments are intentionally manufactured pendants and buttons (Figure 4.1, 4-5, 11-12), along with several fossil mollusc shells (Figure 4.2-3).

The AMH remains recovered from horizon $3_{1}$ a comprise eight teeth, probably belonging to a 7-9-year-old individual (Figure 5). The metric and morphological features demonstrate similarities with Siberian Upper Palaeolithic remains from the Malta, Listvenka and Afontova Gora sites, while also sharing morphological features with modern Native Americans (Viola 2009; Zubova et al. 2017) (Figure 5).

(C) Antiquity Publications Ltd, 2018 


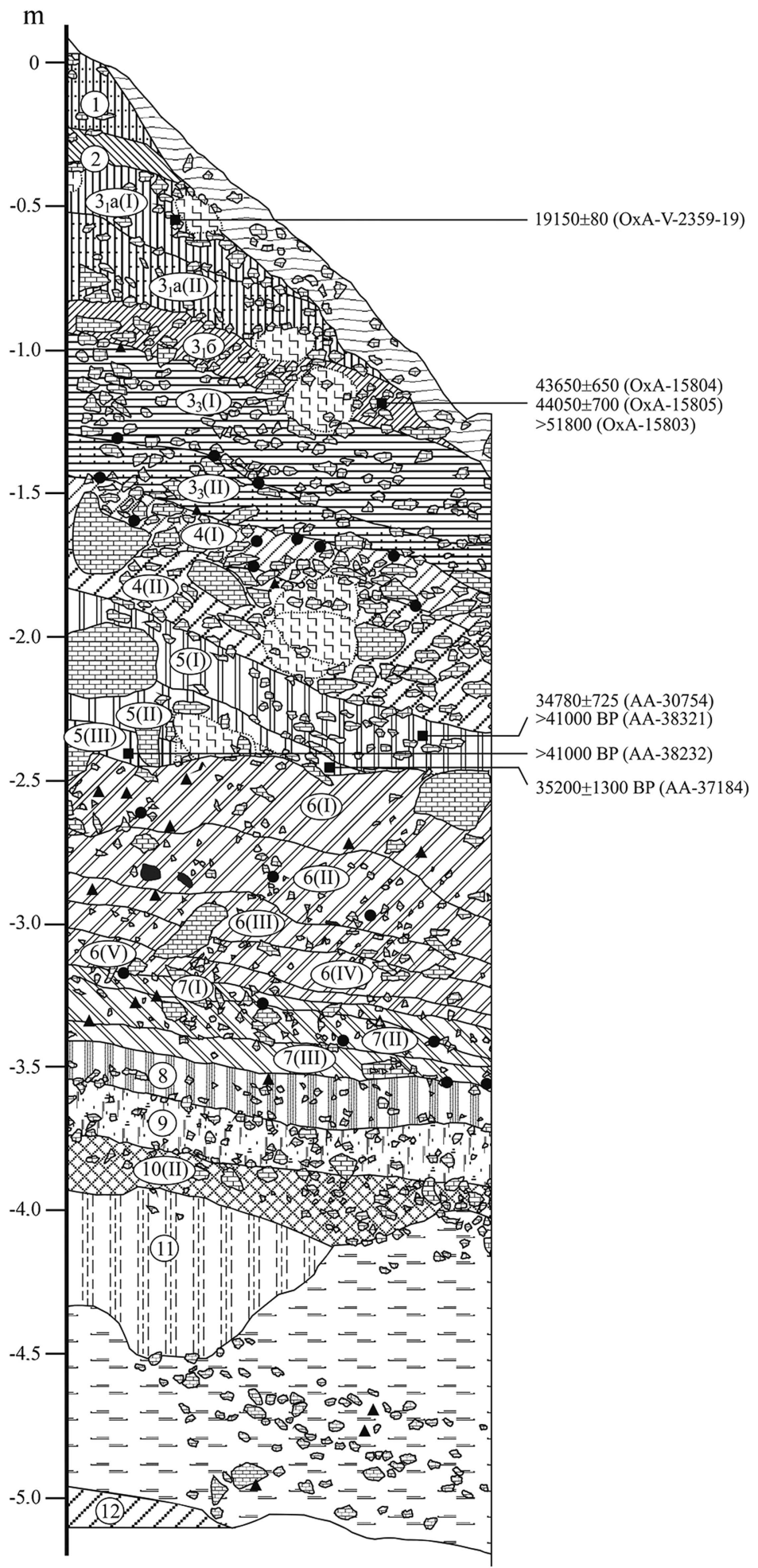

Figure 2. Stratigraphy of Strashnaya Cave (after the 2016 excavation). 

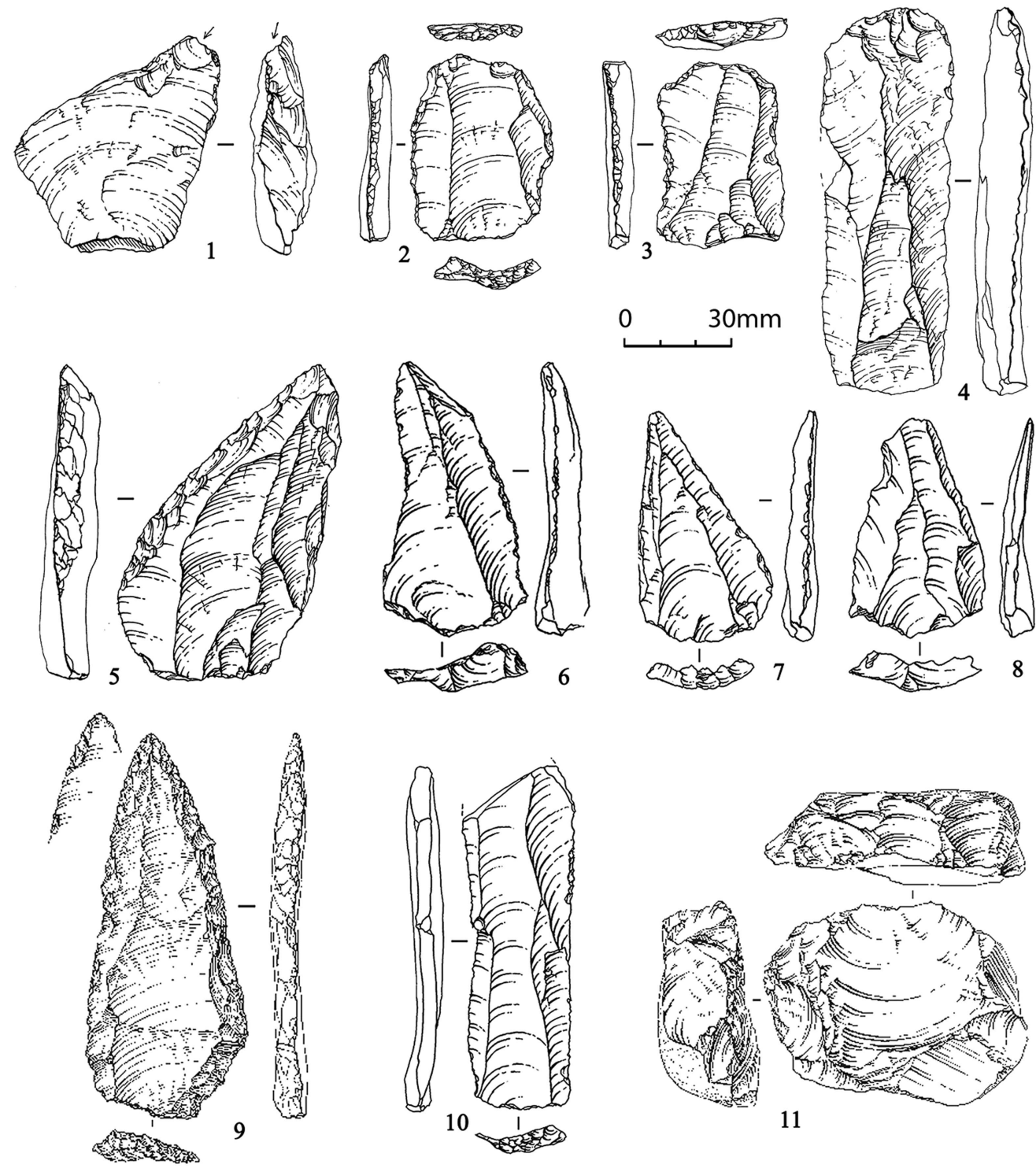

Figure 3. Lithic artefacts from the Middle and Upper Palaeolithic layers of Strashnaya Cave.

The Strashnaya Cave provides new information concerning Middle and Upper Palaeolithic variability in the Altai Mountains. Even without supportive absolute dates, similarities between Strashnaya Cave and Denisovan Middle Palaeolithic techno-complexes suggest that they could be associated. Layer 3 (horizons $3_{1} \mathrm{a}, 3_{1} \mathrm{~b}$ and $3_{3}$ ) characterises three different cultural-chronological phases in the human habitation of the cave. Horizon $3_{3}$ represents the Denisovan phase, as illustrated by radial and Levallois flaking techniques, accompanied by several blade cores, Upper Palaeolithic tool types, ornaments and bone tools (Figure 4.4-5, 9, 16). The second phase, from horizon $3 \mathrm{~b}$, dates to $45 \mathrm{kyr} \mathrm{BC}$, and represents (C) Antiquity Publications Ltd, 2018 


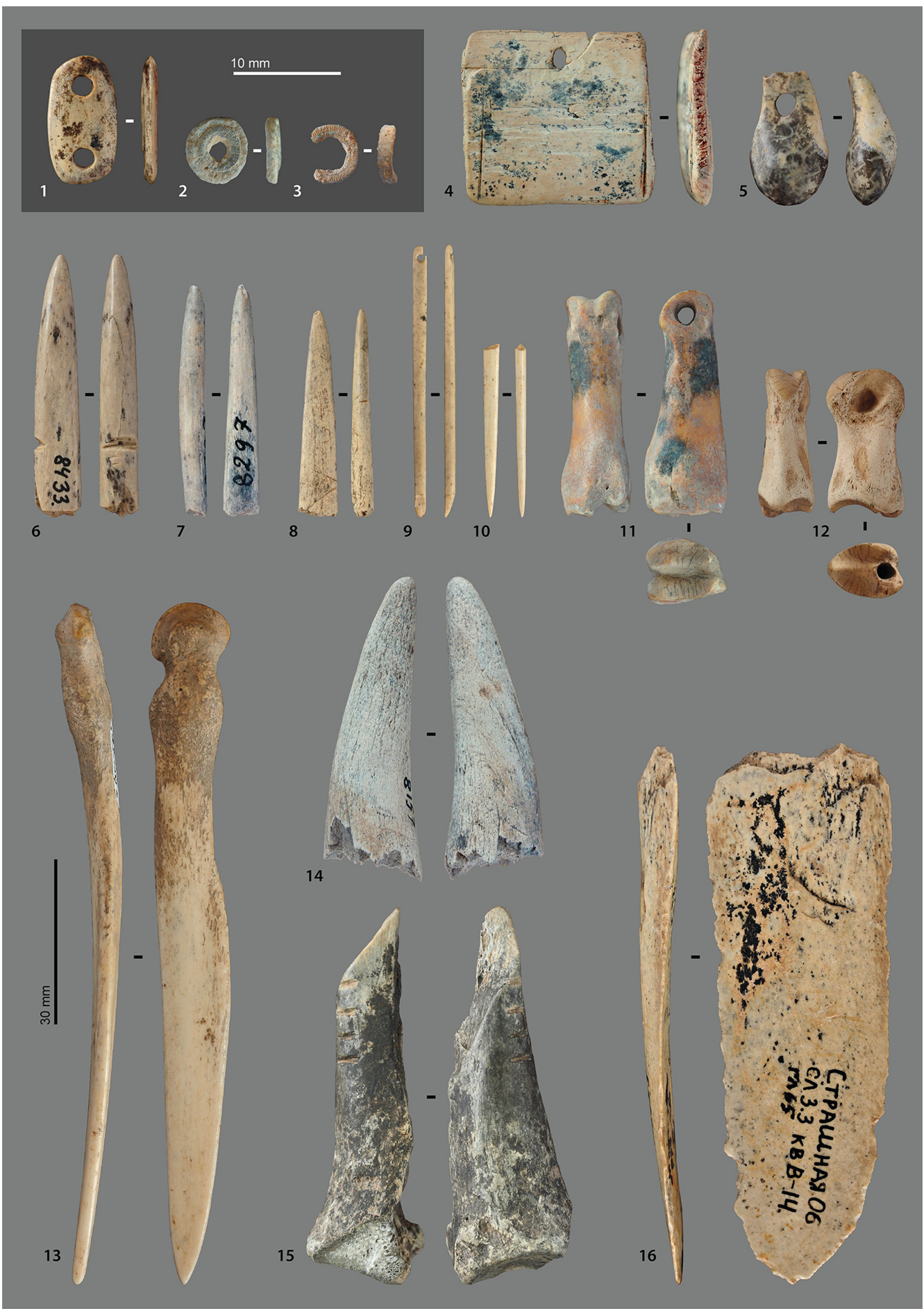

Figure 4. Ornaments and bone tools from the Upper Palaeolithic layers of Strashnaya Cave.

(C) Antiquity Publications Ltd, 2018 


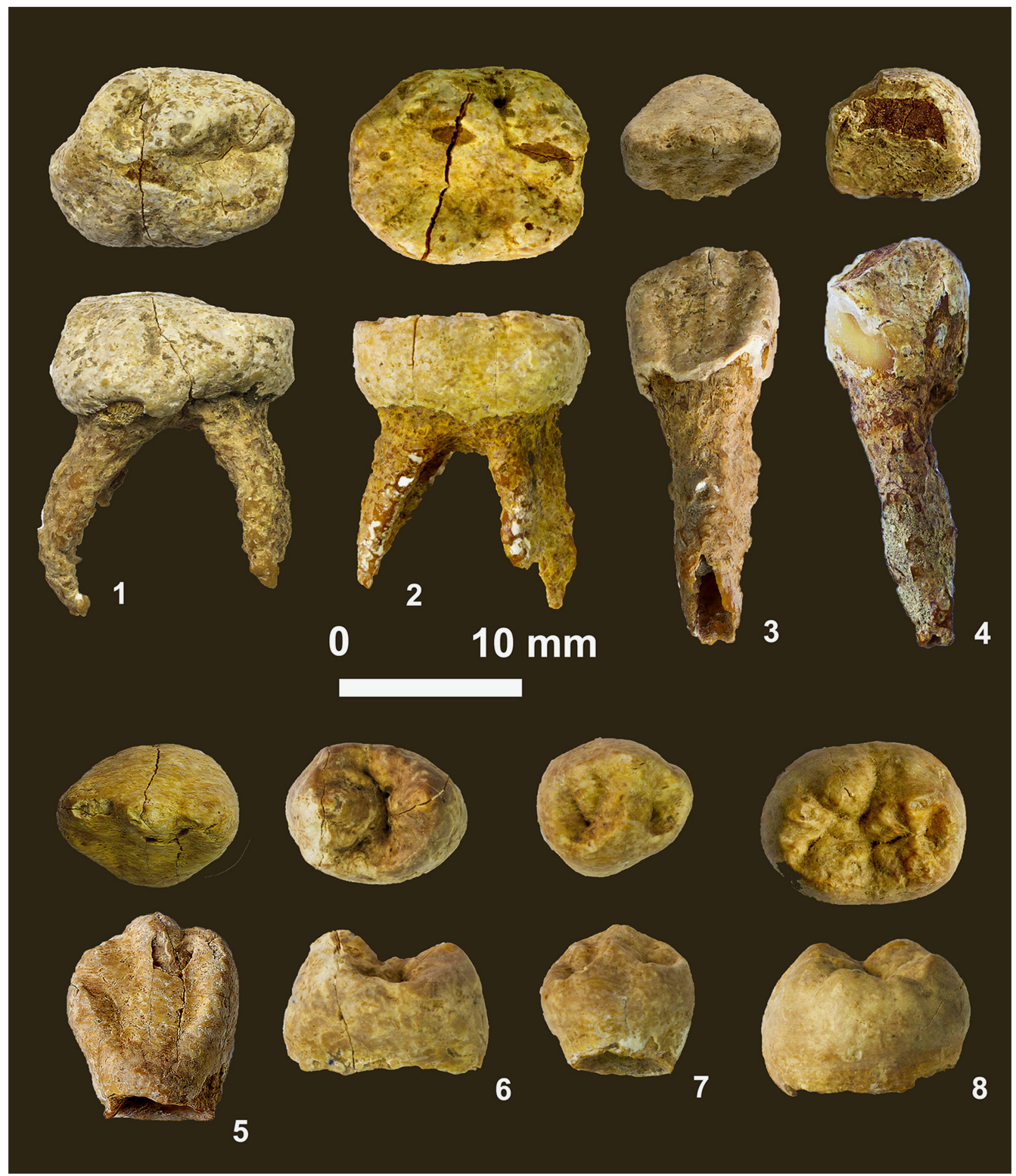

Figure 5. Anthropological remains from Strashnaya Cave.

the Kara-Bom Early Upper Palaeolithic blade-based tradition with bone points (Figure 4.7). The third tradition, from horizon. $3_{1}$ a and dating to $20 \mathrm{kyr}$ BC, represents the advanced Upper Palaeolithic with bladelet technology, personal ornaments and bone tools. To date, bone ornaments (red deer incisor pendants) and bone tools (needles) have only been known in the early chronological context in Denisova Cave (Derevianko et al. 2014). Thus, these finds from Strashnaya Cave significantly complement the evidence for modern behaviour in the region.

(C) Antiquity Publications Ltd, 2018 


\section{Acknowledgements}

Analyses were supported by IAET SB RAS grants 0329-2018-0001 and RFBR 18-09-00041.

\section{References}

Derevianko, A.P., M.V. Shunkov \& S.V. Markin. 2014. The dynamics of the Paleolithic industries in Africa and Eurasia in the Late Pleistocene and the issue of the Homo sapiens Origin. Novosibirsk: Institute of Archaeology and Ethnography SB RAS.

SLON, V. et al. 2017. Neanderthal and Denisovan DNA from Pleistocene sediments. Science 6338: 605-608.

https://doi.org/10.1126/science.aam9695
Viola, B. 2009. New hominid remains from Central Asia and Siberia: the easternmost Neanderthals. Unpublished PhD dissertation, Wien University.

Zubova, A.V., A.I. Krivoshapkin \& A.V.

Shalagina. 2017. Human teeth from the Strashnaya Cave, the Altai Mountains, with reference to the dental variation in Stone Age Siberia. Archaeology, Ethnology and Anthropology of Eurasia 45: 136-45. https://doi.org/10.17746/1563-0110.2017.45. 3.136-145 